\title{
SLEEP QUALITY AND ITS DETERMINANTS AMONG NURSES DURING COVID- 19 PANDEMIC
}

\author{
By \\ Omar DI, Hassan OM and Hani BM \\ Department of Community, Environmental and Occupational Medicine, Faculty of Medicine, \\ Benha University, Egypt.
}

Corresponding author: Omar DI.Email:doaa.omar@fmed.bu.edu.eg

DOI: 10.21608/ejom.2021.82911.1239

Submit date: 2021-07-01 Revise date: 2021-08-06_Accept date: 2021-08-12

Author's contributions: all authors contributed equally in this work.

\begin{abstract}
Introduction: Poor sleep quality is a critical occupational health problem for health care providers, particularly nurses especially during COVID-19 pandemic, that not only affects their physical and mental health, but also affects patient's safety and job performance. Aim of Work: To measure the prevalence of poor sleep quality among Egyptian nurses during the pandemic of COVID 19 and to determine different factors affecting sleep quality. Materials and Methods: This web-based cross-sectional survey was conducted to assess sleep quality and its determinants among Egyptian nurses, during the period from September 2020 to February 2021 using self-administered validated Arabic version of Pittsburgh sleep quality index (PSQI). Results: The current study involved 351 Egyptian nurses, recruited from 15 Egyptian governorates. Most of them were less than 30 years old $(73.2 \%) ; 75.5 \%$ were females and $56.1 \%$ were married. About $17 \%$ of nurses were working in isolation hospitals, $82.1 \%$ were night shifters, and (31.9\%) had COVID-19 infection. Assessment of sleep quality, revealed that $83.5 \%$ had poor sleep quality (PSQI score $>5$ ), the most affected domain was sleep latency $(1.72 \pm 0.86)$, whereas the least affected one was sleep medications use $(0.35 \pm 0.79)$. Poor sleep quality was associated with young age, smokers, work experience less than 10 years, previous COVID-19 infection, working in isolation hospitals, night shifts, private work and long working hours. Conclusion and Recommendations: The current study showed that there was high prevalence of poor sleep quality among the studied nurses during COVID-19 pandemic. Presence of chronic diseases, night shifts, private work and long working hours/week were significant predictors of poor sleep quality among participants which indicated the need for well-organized work schedules for
\end{abstract}


nurses. Work place periodic health assessments and management of sleep disorders are essential, with more attention to wellness and coping programs at all health facilities, especially those involved in fighting COVID-19.

Keywords: Sleep quality, Nurses, Pittsburgh sleep quality index (PSQI), COVID-19 pandemic.

\section{Introduction}

Sleep disorders are becoming a major global public health concern that affects millions of people (Dong et al., 2020). Compared with non-health care providers, medical field workers on the front lines of the COVID-19 pandemic have more sleep disturbances and more inferior sleep quality (San Martin et al., 2020).

Nurses are especially vulnerable to sleep disturbances because they are exposed to various situations that can disrupt sleep quality, such as work schedules (Dong et al., 2017, Ahmed and Hamed, 2020). Nurses, who are the most overworked professional group in an organization, are now compelled to work according to irregular schedules due to health care organizations' efforts to provide high-quality, cost-effective care with minimal staffing (Stanojevic et al., 2016).

These erratic schedules cause poor sleep quality among nursing staff, resulting in physical and mental health issues that impact their professional performance and, as a result, may jeopardize patient safety (Saleh et al., 2014).

Regarding poor sleep quality prevalence among nurses, the average Pittsburgh sleep quality index (PSQI) total score was greater than five in $87.8 \%$ of the night shift workgroup, compared to $56.7 \%$ in the morning shift group $(\mathrm{p}<0.001)$ (Ahmed and Hamed, 2020). According to a study done in Iran, up to $57 \%$ of female shift-working nurses suffer from sleep disturbances (Ghalichi et al., 2013). Irritability, impaired memory, lack of attention in the workplace, work-related accidents or injuries, absence, and even depression can result from a lack of sleep. Sleep deprivation has been linked to metabolic and endocrine disorders, as well as poor health outcomes (Dong et al., 2020 and Kim-Godwin et al., 2021).

\section{Aim of Work}

To measure the prevalence of poor sleep quality among Egyptian nurses during the pandemic of COVID 19 and to determine different factors affecting sleep quality. 


\section{Materials and Methods}

Study design: This is a web-based cross-sectional study.

Place and duration of the study: As data collection during the 2 nd wave of COVID-19 pandemic and social distancing measures are followed to prevent and control the spread of infection, an electronic form (Googleform) of the questionnaire was prepared and distributed to the target group through What's App and Facebook public and private platforms, which are the most common platforms used in Egypt. This study was done during the duration from September 2020 to February 2021

\section{Study sample}

The target population of nurses was recruited according to specific inclusion criteria. Women and men of all ages and qualifications, full-time and permanent employees who worked for at least six months in Egyptian health facilities during the study period and agreed to participate in the study were included.

\section{Sample size:}

The sample size was calculated based on the prevalence of poor sleep quality among nurses reported in a previous Egyptian study by (Ahmed and Hamed, 2020), and it was $72.3 \%$. Considering the $95 \%$ level of confidence and $5 \%$ precision level, the calculated sample size was 308 nurses (Daniel, 1999). The sample size was increased to 351 participants to improve the validity of the study.

Sampling technique: A Snowball non-probability sampling approach was used to reach the target group and attain the required sample size.

\section{Study methods}

An electronic anonymous (Google-form) self - administered Arabic questionnaire was used. The questionnaire was formed of four components as the following:

1- Socio-demographic factors: age -sex-residence-education-marital status- the presence of children at home.

2- Work-related factors: occupation, type of health facility, type of ward they are working in, years of experience, number of night shifts per month, the total working hours per week, and presence of private work.

3- Health-related factors such as smoking history, chronic diseases, a history of having COVID 19 
infection, and symptoms of chronic pain disorders as tension headache, low back, neck, and knee pain. Any pain that lasted more than three months and was either continuous or intermittent, in the past 30 days was considered as chronic pain (Merskey, 1986).

4- Pittsburgh sleep quality index (PSQI) (Suleiman et al., 2010).

The validated Arabic version of the Pittsburgh sleep quality index (PSQI) was used. The Global PSQI's internal consistency reliability is marginally acceptable (Cronbach's alpha =.65). Moderate to high correlations ( $\mathrm{r}=.53$ to.82, p.01) between five PSQI components and the overall PSQI score supported the reliability. The global PSQI correlates strongly with the Insomnia Severity Index $(r=.76)$ and moderately with the related construct of the Medical Outcome Study Short Form-36 vitality subscale $(\mathrm{r}=-.33)$, indicating convergent validity. Pittsburgh sleep quality index contains 24 questions (19 self-rated and five rated by the bed partner). Only the 19 selfrated questions were included in the scoring. These questions are combined to form 7 component scores which are:

(a) Subjective sleep quality, (b) Sleep latency, (c) Sleep duration,(d) Habitual sleep efficiency, (e) Sleep disturbance, (f) Use of sleep medication, (g) Daytime dysfunction.

Each item is scored on a scale of 0 to 3 , with 3 representing the negative extreme on the Likert Scale, and the overall score of the seven components is 0 to 21. A component score of more than or equal to 2 indicates that this component is of poor quality, while a total score of more than 5 indicates poor sleep quality (Garbarino, 1999).

\section{Consent}

An informed written, electronic consent was obtained from all participants after clarification of the objectives of the study, confidentiality of data, voluntary involvement, and withdrawal.

\section{Ethical Aapproval}

The Research Ethics committee (REC), Faculty of Medicine, Benha University, approved the study methodology (Rc.2./.2021).

\section{Data Management}

Data were cleaned and coded then 
analyzed using the Statistical Package as frequency and percent. Correlation for the Social Sciences (SPSS) version 25.0. as data was normally distributed, quantitative data were described in the form of Mean \pm SD. Student t-test was used two means comparisons and ANOVA for comparing more than two groups. Qualitative data were described analysis was performed using Pearson's correlation coefficient (r). Logistic regression analysis was used for the prediction of poor sleep quality. If the $p$-value is $\leq 0.05$, differences were considered statistically significant. 


\section{Results}

Table 1: Sociodemographic characteristics of the studied participants and overall (PSQI) score.

\begin{tabular}{|c|c|c|c|c|c|}
\hline \multicolumn{2}{|c|}{ Variables } & \multirow{2}{*}{$\begin{array}{c}\text { No }(\%) \\
257(73.2 \%)\end{array}$} & \multirow{2}{*}{$\begin{array}{c}\text { PSQI } \\
\text { Mean } \pm \text { SD }\end{array}$} & \multirow{2}{*}{$\begin{array}{c}\begin{array}{c}\text { F or } \mathbf{t} \\
\text { Test }\end{array} \\
3.440\end{array}$} & \multirow{2}{*}{$\begin{array}{c}\text { p } \\
0.033 *\end{array}$} \\
\hline Age groups/ years & $<30$ & & & & \\
\hline & $30-40$ & $67(19.1 \%)$ & $8.49 \pm 3.84$ & & \\
\hline & $>40$ & $27(7.7 \%)$ & $6.62 \pm 3.05$ & & \\
\hline \multirow[t]{2}{*}{ Sex } & Male & $86(24.5 \%)$ & $8.84 \pm 4.03$ & \multirow[t]{2}{*}{.877} & \multirow[t]{2}{*}{0.381} \\
\hline & Female & $265(75.5 \%)$ & $8.41 \pm 3.96$ & & \\
\hline \multirow[t]{2}{*}{ Residence } & Rural area & $246(70.1 \%)$ & $8.41 \pm 3.89$ & \multirow[t]{2}{*}{-.768} & \multirow[t]{2}{*}{0.443} \\
\hline & Urban area & $105(29.9 \%)$ & $8.77 \pm 4.19$ & & \\
\hline \multirow[t]{2}{*}{ Presence of children } & NO & $89(25.4 \%)$ & $8.38 \pm 4.32$ & \multirow[t]{2}{*}{$-.382-$} & \multirow[t]{2}{*}{0.703} \\
\hline & Yes & $262(74.6 \%)$ & $8.56 \pm 3.86$ & & \\
\hline \multirow[t]{4}{*}{ Education } & Nursing school & $46(13.1 \%)$ & $6.82 \pm 3.08$ & \multirow[t]{4}{*}{4.384} & \multirow[t]{4}{*}{$0.005 * *$} \\
\hline & Nursing institute & $187(53.3 \%)$ & $8.45 \pm 3.96$ & & \\
\hline & Nursing bachelor & $89(25.4 \%)$ & $9.25 \pm 4.20$ & & \\
\hline & Post graduate & $29(8.3 \%)$ & $9.37 \pm 3.98$ & & \\
\hline \multirow[t]{2}{*}{ Health facility } & Hospital & $292(83.2 \%)$ & $8.31 \pm 3.91$ & \multirow[t]{2}{*}{4.553} & \multirow[t]{2}{*}{$.034 *$} \\
\hline & Isolation hospital & $59(16.8 \%)$ & $9.52 \pm 4.18$ & & \\
\hline \multirow[t]{7}{*}{ Departments } & Emergency depart & $58(16.5 \%)$ & $7.91 \pm 3.89$ & \multirow[t]{7}{*}{3.187} & \multirow[t]{7}{*}{$0.005 * *$} \\
\hline & ICU & $98(27.9 \%)$ & $9.12 \pm 4.20$ & & \\
\hline & Surgical depart & $28(8.0 \%)$ & $7.14 \pm 3.43$ & & \\
\hline & Medical depart & $49(14.0 \%)$ & $7.28 \pm 3.11$ & & \\
\hline & Pediatric depart & $36(10.3 \%)$ & $10.22 \pm 3.38$ & & \\
\hline & Obs \&Gyn depart & $8(2.3 \%)$ & $8.37 \pm 4.30$ & & \\
\hline & Other departs & $74(21.1 \%)$ & $8.72 \pm 4.32$ & & \\
\hline \multirow[t]{3}{*}{ Experience/years } & $<10$ & $261(74.4 \%)$ & $8.74 \pm 4.03$ & \multirow[t]{3}{*}{3.490} & \multirow[t]{3}{*}{$0.032 *$} \\
\hline & $10-20$ & $57(16.2 \%)$ & $8.47 \pm 4.11$ & & \\
\hline & $>20$ & $33(9.4 \%)$ & $6.81 \pm 2.87$ & & \\
\hline \multirow[t]{2}{*}{ Night shifts $(5.60 \pm 5.34)$} & $\mathrm{NO}$ & $63(17.9 \%)$ & $7.09 \pm 3.50$ & \multirow[t]{2}{*}{10.101} & \multirow[t]{2}{*}{$.002 * *$} \\
\hline & Yes & $288(82.1 \%)$ & $8.83 \pm 4.01$ & & \\
\hline \multirow[t]{2}{*}{ Private work } & $\mathrm{NO}$ & $293(83.5 \%)$ & $8.12 \pm 3.89$ & \multirow[t]{2}{*}{-4.240} & $.000 * *$ \\
\hline & Yes & $58(16.5 \%)$ & $10.50 \pm 3.85$ & & \\
\hline
\end{tabular}

* Significant at the 0.05 level (2-tailed). Obs \&Gyn: Obstetrics and Gynecology
$* *$ Significant at the 0.01 level (2-tailed).

F or t: The used statistical tests ( $\mathrm{F}$ test for ANOVA) 
Table 1 showed that, most of the studied nurses were less than 30 years old (73.2\%); $75.5 \%$ were females. The majority of them $(70.1 \%)$ were from rural areas. Almost half of the studied group were married (56.1\%); $74.6 \%$ had children. Regarding educational level, $53.3 \%$ of participants graduated from the nursing institute, and $25.4 \%$ of them held a Bachelor of Nursing. Nurses from the ICU department accounted for $27.9 \%$ compared to $16.5 \%, 8 \%, 14 \%, 10.3 \%$, and $2.3 \%$ from emergency, surgical, medical, pediatric, obstetrics, and gynecology departments, respectively. About three-quarters of participants had work experience $<10$ years, and $83.5 \%$ of them were involved in private and governmental work. The mean working hours per week was $(37.64 \pm 31.72)$. Most nurses $(82.1 \%)$ were night shifters and the mean night shifts per month were (5.60 \pm 5.34$)$.

Comparison between socio-demographic, work related factors, and the overall (PSQI) score showed that, the mean sleep quality score was significantly higher (poorer sleep quality) among the younger age group $(<30$ years $)(p=0.03)$, with higher educational level (post graduate education) $(\mathrm{p}=0.005)$, working in COVID-19 isolation facilities ( $\mathrm{p}=0.03)$, working in pediatrics and ICU departments $(p=0.005)$, had less than 10 years of experience $(p=0.03)$ and had more night shifts $(p=0.002)$ (Table 1$)$. 
Table 2: Relation between health related factors and overall (PSQI) score.

\begin{tabular}{|c|c|c|c|c|c|}
\hline \multicolumn{2}{|l|}{ Variables } & \multirow{2}{*}{$\begin{array}{c}\text { No }(\%) \\
71(20.2 \%)\end{array}$} & \multirow{2}{*}{$\begin{array}{c}\text { PSQI } \\
\text { Mean } \pm \text { SD } \\
7.80 \pm 4.02\end{array}$} & \multirow{2}{*}{$\begin{array}{l}\text { F or } \mathbf{t} \\
2.902\end{array}$} & \multirow{2}{*}{$\begin{array}{c}\mathbf{p} \\
0.035^{*}\end{array}$} \\
\hline Drinking tea/coffee/cups & No & & & & \\
\hline & $1-2$ & $162(46.2 \%)$ & $8.37 \pm 3.64$ & & \\
\hline & 3- 4 & $91(25.9 \%)$ & $8.80 \pm 4.30$ & & \\
\hline & More than 4 & $27(7.7 \%)$ & $10.33 \pm 4.31$ & & \\
\hline \multirow[t]{3}{*}{ Smoking history } & non smoker & $325(92.6 \%)$ & $8.40 \pm 3.94$ & \multirow[t]{3}{*}{4.503} & \multirow[t]{3}{*}{$0.012 *$} \\
\hline & ex-smoker & $10(2.8 \%)$ & $7.80 \pm 2.89$ & & \\
\hline & Smoker & $16(4.6 \%)$ & $11.37 \pm 4.39$ & & \\
\hline \multirow[t]{2}{*}{ Chronic diseases } & $\mathrm{NO}$ & $243(69.2 \%)$ & $8.01 \pm 3.79$ & \multirow[t]{2}{*}{-3.624} & \multirow[t]{2}{*}{$.000 * *$} \\
\hline & Yes & $108(30.8 \%)$ & $9.65 \pm 4.17$ & & \\
\hline \multirow[t]{2}{*}{ Chronic headache } & $\mathrm{NO}$ & $213(60.7 \%)$ & $7.74 \pm 3.83$ & \multirow[t]{2}{*}{22.004} & \multirow[t]{2}{*}{$.000 * *$} \\
\hline & Yes & $138(39.3 \%)$ & $9.72 \pm 3.92$ & & \\
\hline \multirow[t]{2}{*}{ Chronic neck pain } & $\mathrm{NO}$ & $229(65.2 \%)$ & $8.01 \pm 3.70$ & \multirow[t]{2}{*}{11.235} & \multirow[t]{2}{*}{$.001 * *$} \\
\hline & Yes & $122(34.8 \%)$ & $9.48 \pm 4.30$ & & \\
\hline \multirow[t]{2}{*}{ Chronic low back pain } & $\mathrm{NO}$ & $191(54.4 \%)$ & $7.26 \pm 3.55$ & \multirow[t]{2}{*}{47.029} & \multirow[t]{2}{*}{$.000 * *$} \\
\hline & Yes & $160(45.6 \%)$ & $10.01 \pm 3.95$ & & \\
\hline \multirow[t]{2}{*}{ Chronic knee pain } & NO & $241(68.7 \%)$ & $8.28 \pm 3.80$ & \multirow[t]{2}{*}{2.692} & \multirow[t]{2}{*}{.102} \\
\hline & Yes & $110((31.3 \%)$ & $9.03 \pm 4.32$ & & \\
\hline \multirow[t]{2}{*}{ +ve history of COVID-19 } & NO & $239(68 \%)$ & $8.22 \pm 3.79$ & \multirow[t]{2}{*}{-2.068} & \multirow[t]{2}{*}{$0.039 *$} \\
\hline & Yes & $112(32 \%)$ & $9.16 \pm 4.30$ & & \\
\hline
\end{tabular}

F or t: The used statistical tests (F test for ANOVA).

Table 2 showed that most of the participants were nonsmokers (92.6\%), and almost one-third (30.8\%) had chronic diseases. About one-third of the studied group (32\%) had COVID-19 infection. The overall PSQI-mean score was higher and indicated poorer sleep quality among smokers and tea/coffee drinkers more than 4 cups per day $(\mathrm{p}=0.01,0.04)$. Moreover, those suffering from chronic diseases or complaining of chronic pain (headache, neck pain, or low back pain) had poorer sleep quality $(\mathrm{p}=0.001)$. Also, nurses who had COVID-19 infection revealed lower PSQI scores and poorer sleep quality $(p=0$.04) (Table 2). 
Table 3: Pittsburgh Sleep Quality Index (PSQI) domains and overall score among the studied group.

\begin{tabular}{|c|c|c|c|}
\hline \multicolumn{2}{|c|}{ PSQI domains } & No & $\%$ \\
\hline \multirow[t]{4}{*}{ Subjective sleep quality } & Not during past month & 282 & 80.3 \\
\hline & Less than once/ week & 27 & 7.7 \\
\hline & Once or twice / week & 28 & 8.0 \\
\hline & three or more times / week & 14 & 4.0 \\
\hline \multirow[t]{4}{*}{ Sleep latency(difficulty) } & NO & 25 & 7.1 \\
\hline & Mild- & 117 & 33.3 \\
\hline & Moderate & 138 & 39.3 \\
\hline & Severe & 71 & 20.2 \\
\hline \multirow[t]{4}{*}{ Sleep duration/ hours } & $>7$ & 110 & 31.3 \\
\hline & $6-7$ & 103 & 29.3 \\
\hline & $5->6$ & 90 & 25.6 \\
\hline & $<5$ & 48 & 13.7 \\
\hline \multirow[t]{4}{*}{ Habitual sleep efficiency } & $>85$ & 125 & 35.6 \\
\hline & $75-84$ & 71 & 20.2 \\
\hline & $65-74$ & 97 & 27.6 \\
\hline & $<65$ & 58 & 16.5 \\
\hline \multirow[t]{4}{*}{ Sleep disturbance (difficulty) } & $\mathrm{NO}^{-}$ & 10 & 2.8 \\
\hline & Mild & 197 & 56.1 \\
\hline & Moderate & 124 & 35.3 \\
\hline & Severe & 20 & 5.7 \\
\hline \multirow[t]{4}{*}{ Sleep medication use } & Not during past month & 282 & 80.3 \\
\hline & Less than once / week & 27 & 7.7 \\
\hline & Once or twice / week & 28 & 8.0 \\
\hline & Three or more times / week & 14 & 4.0 \\
\hline \multirow[t]{4}{*}{ Day time dysfunction } & Not during past month & 282 & 80.3 \\
\hline & Less than once / week & 27 & 7.7 \\
\hline & Once or twice / week & 28 & 8.0 \\
\hline & Three or more times / week & 14 & 4.0 \\
\hline \multirow{3}{*}{$\begin{array}{l}\text { Overall score } \\
\text { Mean } \pm \text { SD } \\
8.52 \pm 3.98\end{array}$} & Poor sleep quality (> 5) & 293 & 83.5 \\
\hline & & & \\
\hline & Good sleep quality $(<5)$ & 58 & 16.5 \\
\hline
\end{tabular}


Assessment of sleep quality revealed that 83.5\% (293/351) of studied subjects had poor sleep quality and significant sleep problems (total PSQI score of 5 or above). The mean PSQI score was $(8.52 \pm 3.98)$, the mean sleep duration / hours was (5.85 \pm 0.092$)$, and the habitual sleep efficiency mean was $81.66 \%$ (Table 3 ).

\section{Table 4: Binary logistic regressions for the predictors of poor sleep quality}

\begin{tabular}{|l|c|c|c|c|c|c|}
\hline \multicolumn{1}{|c|}{ Variables } & B & S.E. & Wald & Sig. & Exp(B) & $\begin{array}{c}\text { 95\% C.I. for } \\
\text { EXP(B) }\end{array}$ \\
\hline $\begin{array}{l}\text { Presence of chronic } \\
\text { diseases }\end{array}$ & 1.211 & .404 & 8.962 & $\mathbf{. 0 0 3 * *}$ & 3.356 & $1.519-7.413$ \\
\hline $\begin{array}{l}\text { Presence of night } \\
\text { shifts }\end{array}$ & 1.684 & .389 & 18.695 & $\mathbf{. 0 0 0 * *}$ & 5.387 & $2.511-11.559$ \\
\hline $\begin{array}{l}\text { Presence of private } \\
\text { work }\end{array}$ & $-1.729-$ & .686 & 6.352 & $\mathbf{. 0 1 2 *}$ & .177 & $.046-.681$ \\
\hline Work hours/week & $-.008-$ & .004 & 3.973 & $\mathbf{. 0 4 6 *}$ & .992 & $.984-1.000$ \\
\hline Constant & 1.861 & .751 & 6.144 & $\mathbf{. 0 1 3 *}$ & 6.428 & \\
\hline
\end{tabular}

*:Significant at $<0.05$

$* *$ :Significant at $<0.01$

$\mathrm{B}$ represents the estimated regression coefficients for the explanatory variables, with the standard error (S.E.) given. The Wald statistics is the ratio of B to S.E. of the regression coefficient squared. The significance of each explanatory variable (Sig.) is given by the p-value. Exp (B) is the predicted change in odds for a unit increase in the explanatory variable.

Binary logistic regression analysis was conducted to detect predictors of poor sleep quality, which revealed that the presence of chronic diseases, night shifts, private work, and long working hours/week were significant predictors of poor sleep quality among the studied nurses (Table 4). 


\section{Figure 1: Distribution of subjective causes of poor sleep quality among the studied group.}

\section{Distribution of subjective causes of poor sleep quality}

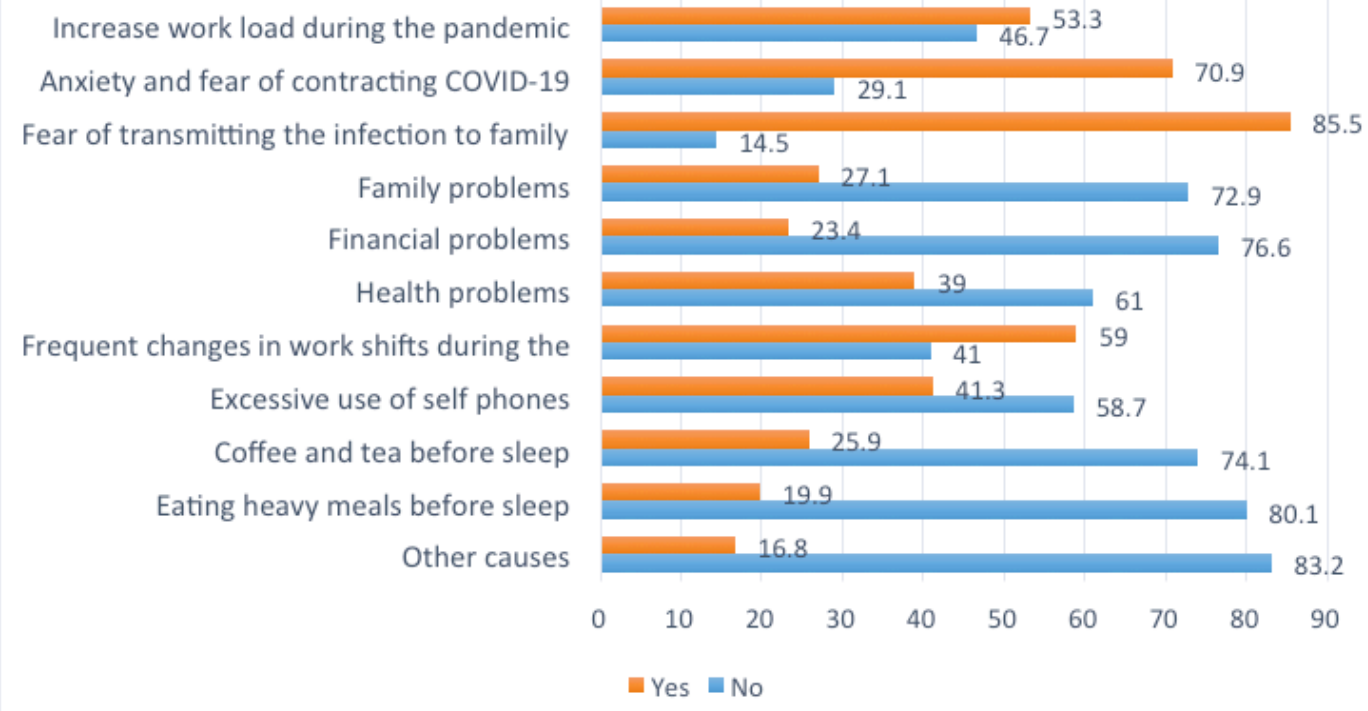

The leading subjective causes of poor sleep quality among nurses were fear of transmitting the infection to family members, anxiety and fear from contracting COVID-19 infection, frequent changes in work shifts, and increased workload during the pandemic (Figure 1).

\section{Discussion}

For healthcare workers, particularly nurses, sleep disorder is a serious occupational health issue that affects their health, patient's safety, and job performance (Ahmed and Hamed, 2020).

The healthcare workers' mental health has always been influenced by epidemics. Nurses and physicians can have poor sleep quality due to stress, depression, and other mental health issues (Salari et al., 2020).

According to recent studies, the prevalence of sleep disruptions during COVID-19 has increased compared to normal times ( $\mathrm{Li}$ et al., 2020). In this context, a survey by Abdulah and 
Musa (2020) found that $68.3 \%$ of Iraqi physicians exposed to COVID-19 suffer from sleep disruptions. In contrast, a similar study in the same region one year earlier, in 2019, found $45.5 \%$ had sleep disturbances (Azzez et al., 2019).

The present study aimed to assess the prevalence of poor sleep quality among nurses working in the Egyptian health care facilities during the COVID-19 pandemic and determine the socio-demographic, health-related, and work-related factors that affect their sleep quality.

According to the findings of the current study, young age nurses (less than 30 years), work experience of 10 years or less, higher educational level (post graduates), who are smokers, and drinking more than 4 cups of tea/coffee/ day, experienced poor sleep quality (Table 1,2). Young age and few working years indicate limited experience and knowledge in managing patients during pandemics such as H1N1 influenza or COVID-19, which could be linked to increased anxiety (Fernandez et al., 2020). Opposite to the current work, Tarhan et al. (2018) on their work on the sleep quality among nurses and its influencing factors, detected that nurses in the older age group (41 years or older) were 9.5 times more likely to have poor sleep quality than nurses in the younger age group (25 years or younger), implying that advanced age is a risk factor for poor sleep quality. The same results were obtained by Salari et al., 2020 in their study on the prevalence of sleep disturbances among physicians and nurses facing the COVID-19 patients. Also, Pérez-Fuentes et al. (2019) reported that increase nurses' age was associated with more inferior sleep quality. He reported that as nurses get older, they sleep for less time, and sleep quality deteriorates. On the other hand; Tu et al. (2020) found no significant relationship between sociodemographic variables (age, marital status, educational level, working years, etc.) and sleep disturbance.

The results of the present study reported higher overall PSQI-mean score and poorer sleep quality among coffee and tea drinkers (more than 4 cups per day). These results were supported by Watson et al., (2016) who conducted a study to determine if caffeine consumption differed between good and poor sleepers, they concluded that poor sleepers reported greater total caffeine consumption compared to good sleepers. This could 
be explained by the fact that, increased caffeine consumption is associated with decreased total sleep time, increased naps, decreased time in bed, daytime sleepiness, and poor subjective sleep quality (Whittier et al., 2014).

The current work detected that nurses who worked in isolation hospitals, involved in private work, worked in the ICU department, and had night shifts were more likely to suffer poor sleep quality (Table 1). Day-shift nurses were less likely to have poor sleep quality. These results agreed with Tarhan et al. (2018), who concluded that nurses who work day shifts get better sleep than nurses who work night shifts, as they were 14.1 times poorer sleep quality than day-shift nurses. Feng et al., 2021in their study on Chinese nurses reported that night shift work was significantly associated with poor sleep quality.

The present study showed that nurses who had COVID-19, chronic diseases as chronic headache, chronic neck pain, or chronic low back pain had a worse sleep quality (Table 2). In terms of the link between poor sleep quality and headache, Liu et al., 2019 found that the most strongly associated factor with sleep disorders among healthcare workers was headache. They concluded that 44.6 percent of their study's participants had been suffering from headaches for more than three months and had not improved in the previous 30 days. The bidirectional link between headaches and sleep problems could explain this finding; while headache treatment is essential for resolving sleep issues; better sleep also reduces headache among healthcare workers. They also confirmed that other types of chronic pain negatively affect sleep, implying that sleep disturbances are more likely when there is chronic pain in various parts of the body (Liu et al., 2019).

About $83 \%$ of the studied nurses were complaining of poor sleep quality during the COVID-19 pandemic in Egypt (Table 3). The observed prevalence was slightly higher than that of another Egyptian study done by Ahmed and Hamed (2020) at Zagazig city, who reported that $73 \%$ of shift group nurses suffered from poor subjective sleep quality.

Also $\mathrm{Tu}$ et al. (2020), found a sleep disturbance prevalence of $(60 \%)$ among nurses (95\% CI: 50.1-69.1\%) in their study on sleep quality and mood symptoms in conscripted frontline nurse 
in Wuhan, China during COVID-19 outbreak. The results of current work was also higher than that obtained by Zhou et al. (2020) in their work on the prevalence and demographic correlates of poor sleep quality among frontline health professionals in Liaoning Province, China during the COVID-19 outbreak, who detected that the prevalence was (19.5\%, 95\% CI: 17.6-21.54\%).

Egyptian nurses' high sleep disturbance prevalence during the COVID-19 pandemic can be explained by the fact that Egyptian nurses were under a lot of stress at work and had to work longer hours due to the rising number of COVID-19-infected patients in Egypt and a shortage of nursing staff. The heavy workload had a significant impact on their sleep quality, as did negative feelings such as fear of becoming infected and spreading COVID-19 to their friends, colleagues, and family. In COVID-19 isolation hospitals, many nurses were separated from their families and communities. This condition could lead to a lack of social support, which could lead to sleep disturbances (Zhou et al., 2020).

The mean overall PSQI score among studied nurses was $8.52 \pm 3.98$, reflecting poor sleep quality (Table 3 ) which was higher than the mean total PSQI score of a survey conducted in Istanbul on 152 nurses before COVID-19 pandemic, which was $6.65 \pm 3.48$ (Tarhan et al., 2018). This discrepancy can be explained by the fact that nurses during the COVID-19 pandemic experience more stress, leading to poor sleep quality.

Binary logistic regression analysis in the present study concluded that the presence of chronic diseases, night shifts, private work, and long working hours were significant predictors of poor sleep quality among the studied nurses (Table 4). This finding is in line with a study done by Dong et al. (2017) and Alamri et al. (2019), who detected that long working hours were related to poor sleep quality.

In contrast to a study was done in Amman on 186 nurses by Suleiman etal., 2010; who found no link between PSQI scores and socio-demographic variables like age group, gender, educational level, marital status, dependent children, and dependent adults. Furthermore, no significant link was observed between PSQI scores and work-related variables like nurse experience, hospital type, shift duration, and shift system. The only significant link was between PSQI 
scores and monthly pay for nurses. This could be attributed to the presence of correlation between some dimensions of quality of work life. If employees are satisfied with their income and have no financial problems, find their work environment secure, have the necessary opportunity for growth and promotion, and are provided with job security, their quality of sleep is likely to increase as a result of these parameters (Momeni et al., 2016).

Conclusion and Recommendations: The prevalence of poor sleep quality among Egyptian nurses during the COVID-19 pandemic is high, factors as lower educational level, young age, work experience less than ten years, multiplenight shifts, working in isolation hospitals, long working hours, private work in addition to the governmental one, and had COVID-19 infection were significantly associated with poor sleep quality among the studied group. This indicates the urgent need for wellorganized work schedules for nurses, work place periodic health assessments and management of sleep disorders are essential, with more attention to wellness and coping programs at all health facilities, especially those involved in fighting COVID-19.

\section{Funding}

This work was not funded by any agencies.

\section{Conflict of interest}

We have no competing of interest to disclose.

\section{Acknowledgment}

We would like to thank all Egyptian nurses who participated in this study.

\section{References}

1-Abdulah DM and Musa DH (2020): Insomnia and stress of physicians during COVID19outbreak. Sleep Med; 1:2.https://doi. org/10.1016/j.sleepx.2020.100017.

2-Ahmed AS and Hamed RA (2020): Sleep disorder among shift work nurses and its impact on their quality of life at Al Ahrar Governmental Hospital, Zagazig City, Egypt. Egypt J Psychiatr; 41:117-24. DOI: 10.4103/ejpsy.ejpsy_33_20.

3-Alamri AF, Amer AS, Almubarak A and Alanazi H (2019): Sleep Quality among Healthcare Providers; In Riyadh, 2019. IJMSCI; 6(05): 4438-48. https://doi.org/10.18535/ijmsci/ v6i5.03.

4-Azzez SS, Abdulah DM and Piro RS (2019): Sleep severity and fatigue manifestations in relation to the doctor-patient relationship. Sleep Med; 58:13-7. https://doi.org/10.1016/j. sleep.2019.02.015

5-Daniel WW (1999): Biostatistics: a foundation for analysis in the health sciences. 7th ed. New York: John Wiley \& Sons .Available at: www. wiley.com/college/daniel

6-Dong H, Zhang Q, Sun Z, Sang F and Xu Y (2017): Sleep problems among Chinese clinical nurses working in general hospitals. Occup Med (Lond); 67:534-9. 
7-Dong H, Zhang Q, Zhu C and Lv Q (2020): Sleep quality of nurses in the emergency department of public hospitals in China and its influencing factors: a cross-sectional study. Health Qual Life Outcomes; 18(1):116. Doi: 10.1186/s12955020-01374-4. PMID: 32349759; PMCID: PMC7191763.

8-Feng HL, Qi XX, Xia CL, Xiao SQ and Fan L (2021): Association between night shift and sleep quality and health among Chinese nurses: A cross-sectional study. J Nurs Manag; 100:1-9. Doi: 10.1111/jonm.13351. PMID: 33908108.

9-Fernandez R, Lord H and Halcomb E (2020): Implications for COVID-19: systematic reviews of nurses' experiences of working in acute care hospital settings during a respiratory pandemic. Int J Nurs Stud; 111:103637. Doi: 10.1016/j.ijnurstu.2020.103637.

10-Garbarino S (1999): Sleep disorders and day sleepiness in a population of work-shifters of the State Police Centro di Medicina del Sonno, D.I.S.M. Univ Genova GItal Med Lav Ergon, 21:13-9.

11-Ghalichi L, Pournik O, Ghaffari M and Vingard E (2013): Sleep quality among health care workers. Arch Iran Med; 16(2):100-3. PMID: 23360632.

12-Kim-Godwin YS, Lee MH, Logan JG and Liu X (2021): Factors Influencing Sleep Quality among Female Staff Nurses during the Early COVID-19 Pandemic in the United States. Int J Environ Res Public Health; 18: 4827. https:// doi.org/10.3390/ijerph18094827.

13-Li Y, Qin Q, Sun Q, Sanford LD, Vgontzas AN and Tang X (2020): Insomnia and psychological reactions during the COVID-19 outbreak in China. J Clin Sleep Med; 16(8):1417-8. Doi: $10.5664 / \mathrm{jcsm} .8524$.

14-Liu H, Liu J and Chen M (2019): Sleep problems of healthcare workers in tertiary hospital and influencing factors identified through a multilevel analysis: a cross-sectional study in China. BMJ Open; 9: e032239. Doi: 10.1136/ bmjopen-2019-032239.
15-Merskey H (1986): International Association for the Study of Pain: classification of chronic pain. Descriptions of chronic pain and syndromes definitions of pain terms. Pain ;3: S1-226.

16-Momeni B, Shafipour V, Esmaeili R and YazdaniCharati J (2016): The relationship between the quality of work life and sleep in nurses at the intensive care units of teaching hospitals in Mazandaran, Iran. JNMS; 1) ${ }^{\boldsymbol{r}}$ ): 28-34.

17-Pérez-Fuentes C, Molero Jurado M, Simón Márquez M and Gázquez Linares J (2019): Analysis of sociodemographic and psychological variables involved in sleep quality in nurses. Int J Environ Res Public Health; 16(20):3846.

18-Salari N, Khazaie H, Hosseinian-Far A, Ghasemi H, Mohammadi M, et al. (2020): The prevalence of sleep disturbances among physicians and nurses facing the COVID-19 patients: a systematic review and meta-analysis. Global Health; 16(1): 1-14.

19-Saleh MA, Awadalla NJ, El-masri JM and Sleem WF (2014): Impact of nurses' circardian rhythm sleep disorders, fatigue and depression on medication administration errors. Egypt J Chest Dis Tuberc; 63:145-53.

20-San Martin AH, Serrano JP and Cambriles TD (2020): Sleep characteristics in health workers exposed to the COVID-19 pandemic. Sleep Med; 75:388-94. Doi: 10.1016/j.sleep.2020.08.013.

21-Stanojevic C, Simic S and Milutinovic D (2016): Health effects of sleep deprivation on nurses working shifts. Med Pregl; 69(5-6):183-8. Doi: 10.2298/mpns1606183s.

22-Suleiman KH, Yates BC, Berger AM, Pozehl B and Meza J (2010): Translating the Pittsburgh sleep quality index into Arabic. West J Nurs Res ;32(2): 250-68 https://doi. org/10.1177/0193945909348230

23-Tarhan M, Aydin A, Ersoy E and Dalar L (2018): The sleep quality of nurses and its influencing factors. Eurasian J Pulmonol ; 20(2): 78.

24-Tu Z-h, He J-w and Zhou N (2020): Sleep quality and mood symptoms in conscripted frontline nurse in Wuhan, China during 
COVID-19 outbreak: a cross-sectional study. Medicine; 99(26): e20769. Doi: 10.1097/ MD.0000000000020769

25-Watson EJ, Coates AM, Kohler M and Banks

S (2016): Caffeine Consumption and Sleep Quality in Australian Adults. Nutrients; $)^{\wedge}$ ): 479. https://doi.org/10.3390/nu8080479

26-Whittier A, Sanchez S, Castañeda B, Sanchez E, Gelaye B, et al.(2014): Eveningness Chronotype,
Daytime Sleepiness, Caffeine Consumption, and Use of Other Stimulants Among Peruvian University Students. J Caffeine Res; 4(1):21-7. 27-Zhou Y, Yang Y and Shi T (2020): Prevalence and Demographic Correlates of Poor Sleep Quality among Frontline Health Professionals in Liaoning Province, China During the COVID-19 Outbreak. Front Psychiatry; 11:520. Doi:10.3389/fpsyt.2020.00520. 
